Revista Perspectivas Online: Exatas \& Engenharia Agosto de 2019, v.09, n.25, p. 49 - 76 ISSN: 2236-885X (Online) DOI: $10.25242 / 885 X 92520191867$

\title{
DIMENSIONAMENTO DE UMA TURBINA A GÁS DE EIXO AXIAL PARA UM AVIÃO DE PEQUENO PORTE
}

\author{
Alice Lubanco Leal Barros ${ }^{1 *}$, Ygor Peixoto Rangel, João Marcelo Cardoso Carvalho ${ }^{1}$, \\ Bárbara Ferreira de Oliveira ${ }^{1} \&$ Silvio Eduardo Teixeira Pinto da Silva ${ }^{1}$
}

\section{RESUMO}

BARROS, A.L.L; RANGEL, Y.P.; CARVALHO, J.M.C.; OLIVEIRA, B.F.; SILVA, S.E.T.P. Dimensionamento de uma turbina a gás de eixo axial para um avião de pequeno porte. Perspectivas Online: Exatas \& Engenharia, v. 09, n.25, p. 49 - 76, 2019.

Com o crescimento da aviação comercial surge a necessidade de se investir em projetos de dimensionamento de turbinas a gás de modo a se obter um melhor rendimento do motor de propulsão através da redução perdas ao longo da turbina. Nesse contexto, o presente trabalho tem como objetivo dimensionar um compressor e uma turbina de propulsão de eixo axial para um avião a jato do tipo Phenom 300E. Para cumprir tal objetivo foram realizados cálculos que possibilitam determinar: a taxa de compressão e expansão no compressor e na turbina respectivamente; a temperatura e a velocidade de entrada e saída em cada estágio do compressor e da turbina; a geometria das pás do rotor e estator do compressor e da turbina; o número de estágios em cada um e; a área na entrada e saída do compressor e da turbina. Para o dimensionamento foram utilizados dados de velocidade e altura de cruzeiro fornecidos pelo fabricante do avião. Foi possível determinar que em sete estágios de compressão o compressor axial projetado consegue atingir a razão de compressão de 8 arbitrada inicialmente, aumentando a pressão e temperatura ao longo dos estágios à medida que as alturas e ângulos das palhetas estatoras e rotoras variam enquanto que na turbina foram necessários apenas dois estágios de expansão para conseguir gerar a energia necessária para o compressor e para o empuxo do avião.

Palavras-chave: aviação; compressor; número de Mach. 


\begin{abstract}
With the growth of commercial aviation, arises the need to invest in gas turbine design projects in order to obtain a better propulsion engine efficiency through the reduction of losses along the turbine. In this context, the present work aims to size a compressor and an axial-axis propulsion turbine for a Phenom 300E jet aircraft. In order to fulfill this objective, the calculations are presented that allow to determine: the rate of compression and expansion in the compressor and in the turbine respectively; the temperature and speed of entry and exit at each stage of the compressor and the turbine; the geometry of the rotor blades and compressor and

turbine stator; the number of stages in each; and the area at the inlet and outlet of the compressor and in the turbine. The sizing was based on the cruising speed and height data provided by the airplane manufacturer. It was possible to determine that at seven stages of compression the designed axial compressor can reach the initial rate of compression of 8 , increasing the pressure and temperature along the stages, as the heights and angles of the stator and rotor vanes vary while in the turbine only two stages of expansion were necessary to generate the energy needed for the compressor and the buoyancy of the airplane.
\end{abstract}

Keywords: aviation; compressor; Mach number.

${ }^{1}$ Institutos Superiores de Ensino do CENSA - ISECENSA - Laboratório de Análise e Projetos de Sistemas Mecânicos LAPSIM - Rua Salvador Correa, 139, Centro, Campos dos Goytacazes, RJ, CEP: 28035-310, Brasil;

(*) e-mail: lubanco.alice@gmail.com

Data de recebimento: 11/09/19. Aceito para publicação: 11/09/19.

Persp. Online: exatas \& eng., Campos dos Goytacazes, 25 (09) 49 - 76 - 2019

seer.perspectivasonline.com.br 


\section{INTRODUÇÃO}

Com o avanço da tecnologia a quantidade de energia requerida aumenta, sendo fundamental o uso de turbinas no processo de geração de energia, as quais são importantes equipamentos que utilizam a energia do fluido para a geração de eletricidade ou potência mecânica. Estes equipamentos se destacam por serem um dos tipos de motores mais utilizados no mundo. No caso específico, as aeronaves utilizam as turbinas a gás devido a sua alta relação potência/peso, o que possibilita minimizar o consumo de combustível (MASCHIETTO, 2014).

$\mathrm{Na}$ aviação comercial, a maioria dos projetos utiliza turbinas a gás denominada por turbofan, sendo inicialmente concebida para melhorar o rendimento do motor de propulsão por meio da redução da velocidade média do seu jato. Este tipo de motor é particularmente adequado para velocidades subsônicas e consiste basicamente na adição de um ventilador (fan) ao motor a jato simples, de forma que uma parcela do caudal de ar total (caudal bypass) contorne o core do motor antes de ser expelido através de uma tubeira de escape (RIBEIRO, 2012).

As turbofans são formadas por compressores, câmaras de combustão e turbina. Sua classificação é baseada no tipo de compressor dinâmico utilizado, podendo ser de fluxo centrífugo, axial ou misto. As turbofans de fluxo axial apresentam performance mais eficiente quando comparadas às centrífugas, porém são mais sensíveis a problemas de angulação das pás e refluxo que pode provocar a interrupção do fluxo e a perda de sustentação durante o voo.

Tendo em vista a importância da turbina na aviação comercial, neste trabalho serão preparados e apresentados os cálculos necessários para o projeto de uma turbina a gás de eixo axial para um avião do tipo Phenom 300E da Embraer. Serão detalhados os cálculos das principais propriedades e balanços de energia a fim de descrever os processos intrínsecos do escoamento do ar durante os estágios de compressão e expansão dos gases no interior da turbina.

\section{METODOLOGIA}

Para o dimensionamento do turbofan inicialmente serão apresentados os principais parâmetros de projeto e operação do avião a jato Phenom 300 da Embraer. O avião executivo da categoria light foi o mais vendido do mundo por seis anos consecutivos, possuindo capacidade para 7 passageiros e um piloto, sendo que dentre os jatos disponíveis no mercado é o que apresenta velocidade superior e maior altitude (EMBRAER, 2019). A Figura 1 ilustra o jato executivo em perspectiva isométrica.

Persp. Online: exatas \& eng., Campos dos Goytacazes, 25 (09) 49 - 76 - 2019 


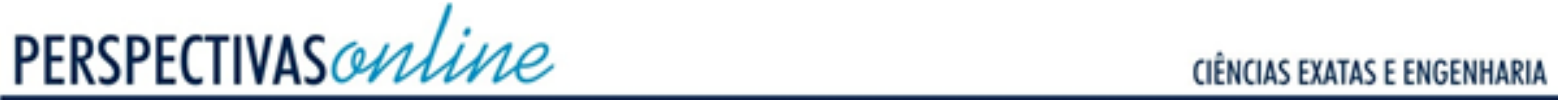

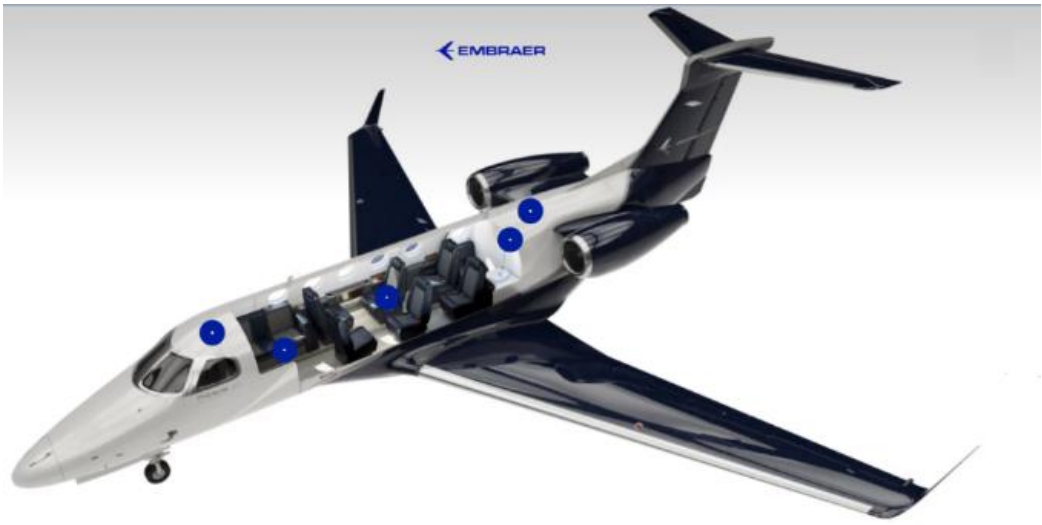

Figura 11: Vista em perspectiva do jato executivo da Embraer.

Fonte: Embraer, 2019.

Os dados da Tabela 1 são fornecidos para quando o avião atingir a altitude de cruzeiro em torno de 13716 m, conforme orientação da Embraer.

Tabela 1: Dados usados no projeto do Turbofan

\begin{tabular}{ll}
\hline Parâmetros & Valores \\
\hline Velocidade de cruzeiro $\left(\boldsymbol{C}_{\mathbf{1}}=\boldsymbol{C}_{\boldsymbol{a} \mathbf{1}}\right)$ & $233 \mathrm{~m} / \mathrm{s}$ \\
\hline Razão do By-pass & 3,3 \\
\hline Diâmetro médio da entrada do motor & $0,716 \mathrm{~m}$ \\
\hline Altura de cruzeiro & $13716 \mathrm{~m}$ \\
\hline Temperatura de estagnação $\left(\boldsymbol{T}_{\mathbf{0 1}}=\boldsymbol{T}_{\boldsymbol{a}}\right)$ & $216,5 \mathrm{~K}$ \\
\hline Pressão $\left(\boldsymbol{P}_{\mathbf{0 1}}=\boldsymbol{P}_{\boldsymbol{a}}\right)$ & $1,211104 \mathrm{~N} / \mathrm{m}^{2}$ \\
\hline Densidade do ar & $0,1948 \mathrm{~kg} / \mathrm{m}^{3}$ \\
\hline Carga máxima & $1196 \mathrm{~kg}$ \\
\hline
\end{tabular}

\subsection{Fundamentos teóricos}

A turbina proposta é composta de três componentes principais: compressor, câmara de combustão e turbina.

\subsubsection{Compressor}

O compressor analisado foi do tipo axial formado por um ou mais estágios de compressão, sendo cada estágio composto por um par rotor/estator, onde o fluido de trabalho escoa paralelo ao eixo do rotor (PINTO, 2010). O estator é formado por palhetas estacionárias, enquanto o rotor é envolvido por uma série de palhetas móveis.

Conforme Pinto (2010), o ar é acelerado pelo rotor e desacelerado pelo estator (Figura 2), onde a energia cinética é convertida em entalpia com consequente ganho de pressão estática. Este processo é repetido em outros estágios até que a razão de pressão desejada seja alcançada.

Persp. Online: exatas \& eng., Campos dos Goytacazes, 25 (09) 49 - 76 - 2019 seer.perspectivasonline.com.br 


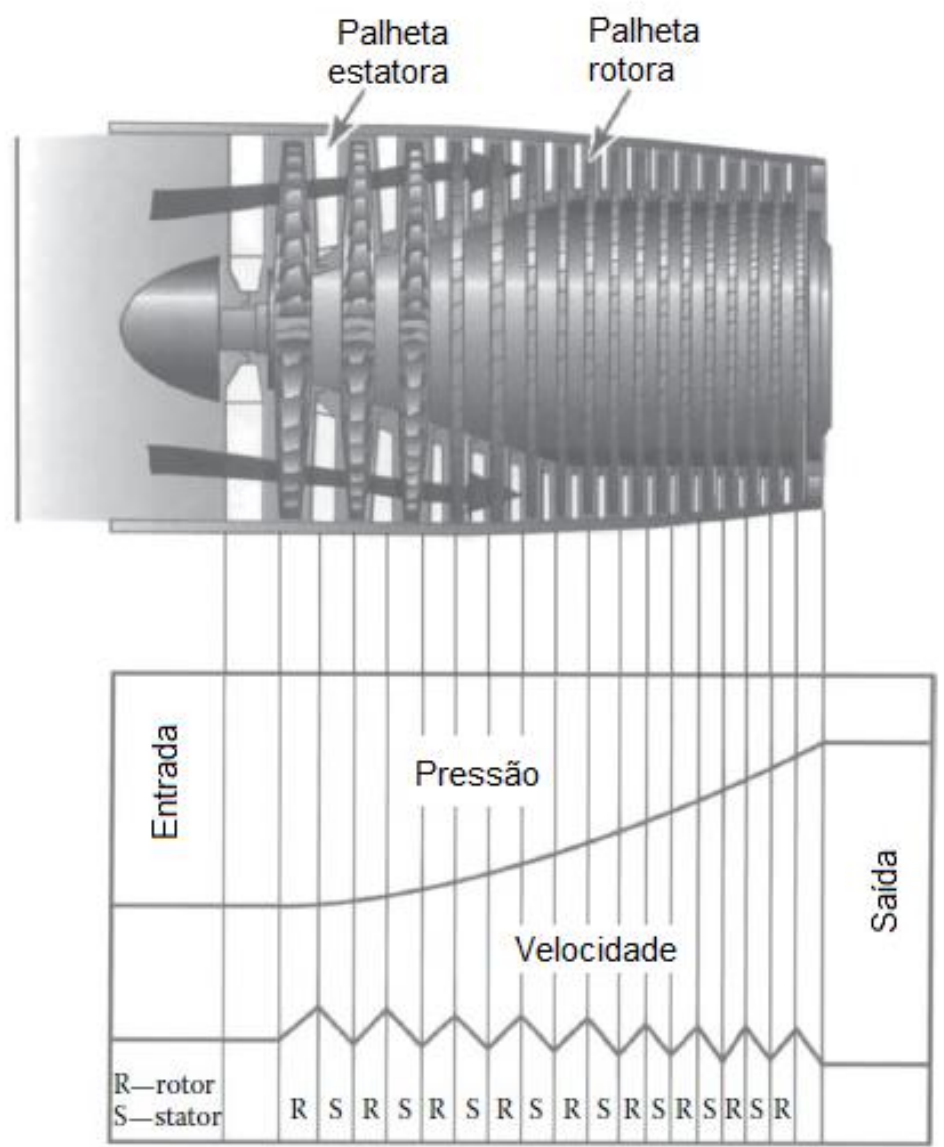

Figura 2: Perfil da velocidade e pressão do ar durante os estágios de compressão. Fonte: El-Sayed, 2017.

Em cada estágio do compressor axial, a elevação da pressão é bem pequena por causa dos limites de difusão impostos pelo processo que é sujeito a um gradiente adverso de pressão. Este efeito pode causar descolamento e fluxo reverso quando o compressor estiver operando fora das condições de projeto. Para aumentar a eficiência do compressor, é importante que o aumento de pressão no rotor seja o maior possível (PINTO, 2010). Dessa forma, os compressores axiais possuem vários estágios para garantir uma maior razão de pressão.

Os dados do compressor utilizado no presente projeto são apresentados na Tabela 2.

Tabela 2: Dados de projeto para o compressor

\begin{tabular}{lc}
\hline Dados & Valores \\
\hline Razão de compressão $\left(\boldsymbol{R}_{\boldsymbol{p}}\right)$ & 8 \\
\hline Razão do raio $(\boldsymbol{r} / \boldsymbol{R})$ & 0,5 \\
\hline Calor específico do ar $(\mathrm{cp})$ & $1,005 \mathrm{~kJ} / \mathrm{kgK}$ \\
\hline Coeficiente politrópico do ar $(\mathrm{k})$ & 1,4 \\
\hline eficiência & $90 \%$ \\
\hline
\end{tabular}

Persp. Online: exatas \& eng., Campos dos Goytacazes, 25 (09) 49 - 76 - 2019 seer.perspectivasonline.com.br 
O compressor real apresenta uma eficiência $\eta$ equivalente a $90 \%$ e que deve ser levada em consideração para que os dados obtidos se aproximem dos valores reais. Essa eficiência define que de toda a energia entregue ao compressor, apenas parte dela será transmitida ao fluido (LOPES, 2007).

\subsubsection{Determinação do número de estágios}

No compressor, o rotor acelera o fluido enquanto o estator eleva a pressão do mesmo, de forma que esta aumenta pouco a pouco em cada estator. Isso significa que existe um número de estágios no compressor até a pressão aumentar pela razão de compressão, sendo necessário determinar a quantidade de estágios necessária para que a taxa de compressão seja atingida (ÇENGEL e CIMBALA, 2012).

Para isso, é feita uma razão entre a elevação de temperatura no compressor e a variação média por estágio. A elevação da temperatura de estagnação total do ar é calculada a partir da Equação 1, independentemente da quantidade de perdas ou da eficiência de compressão (SARAVANAMUTTOO et al., 2006).

$$
\Delta T o=T o_{2}-T o_{1}
$$

Já a elevação média de temperatura de estagnação em cada estágio pode ser determinada a partir dos ângulos médios, conforme a Equação 2.

$$
\Delta T o_{m}=\frac{U \cdot C_{a} \cdot\left(\tan \beta_{1}-\tan \beta_{2}\right)}{c_{p}}
$$

Onde $c_{p}$ é o calor específico do gás, $U$ a velocidade perférica média, $C_{a}$ a velocidade axial, os ângulos $\beta$ são os ângulos construtivos das pás que são encontrados utilizando o triângulo de velocidades.

A Equação 3 define o número de estágios do compressor.

$$
n \text { o de estágios }=\frac{\Delta T o}{\Delta T o_{m}}
$$

\subsubsection{2 Ângulos de saída para cada estágio}

Para o cálculo dos ângulos, é utilizado o triângulo de velocidades, que é uma relação geométrica usada para definir as angulações entre os vetores de velocidade dentro das turbomáquinas como mostra a Figura 3 (WHITE, 2011).

Assumindo $C_{a}=C_{a_{1}}=C_{a_{2}}$, as Equações 4,5 e 6 seguem imediatamente da geometria e do triângulo de velocidades, mostrando como encontrar os ângulos. Então:

Persp. Online: exatas \& eng., Campos dos Goytacazes, 25 (09) 49 - 76 - 2019 seer.perspectivasonline.com.br 


$$
\begin{gathered}
\frac{U}{C_{a}}=\tan \left(\alpha_{1}\right)+\tan \left(\beta_{1}\right)=\tan \left(\alpha_{2}\right)+\tan \left(\beta_{2}\right) \\
\beta=\operatorname{sen}^{-1}\left(\frac{U-C_{W}}{V}\right)=\cos ^{-1}\left(\frac{C_{a}}{V}\right)=\tan ^{-1} \frac{U-C_{W}}{C_{a}} \\
\alpha=\operatorname{sen}^{-1}\left(\frac{U-V_{W}}{C}\right)=\cos ^{-1}\left(\frac{C_{a}}{C}\right)=\tan ^{-1} \frac{U-V_{W}}{C_{a}}
\end{gathered}
$$

Onde $U$ é a velocidade periférica, $C_{a}$ a axial, $C_{W}$ a velocidade tangencial, $V$ a velocidade relativa e os ângulos são os de entrada ou saída.

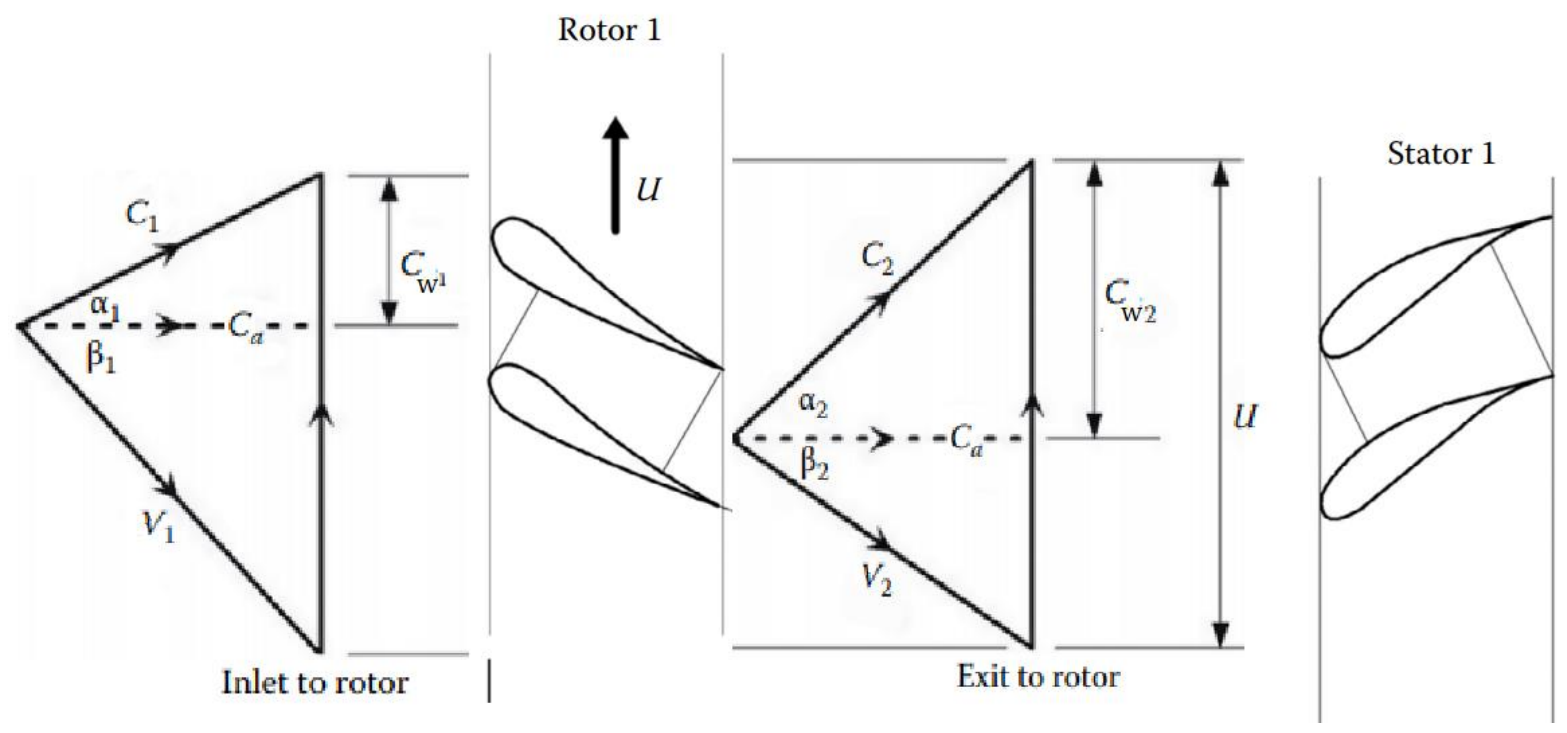

Figura 3: Triângulo de velocidades.

Fonte: El-Sayed, 2017.

Assumindo $C_{a}=C_{a_{1}}=C_{a_{2}}$, as Equações 4, 5 e 6 seguem imediatamente da geometria e do triângulo de velocidades, mostrando como encontrar os ângulos. Então:

$$
\begin{gathered}
\frac{U}{C_{a}}=\tan \left(\alpha_{1}\right)+\tan \left(\beta_{1}\right)=\tan \left(\alpha_{2}\right)+\tan \left(\beta_{2}\right) \\
\beta=\operatorname{sen}^{-1}\left(\frac{U-C_{W}}{V}\right)=\cos ^{-1}\left(\frac{C_{a}}{V}\right)=\tan ^{-1} \frac{U-C_{W}}{C_{a}} \\
\alpha=\operatorname{sen}^{-1}\left(\frac{U-V_{W}}{C}\right)=\cos ^{-1}\left(\frac{C_{a}}{C}\right)=\tan ^{-1} \frac{U-V_{W}}{C_{a}}
\end{gathered}
$$

Onde $U$ é a velocidade periférica, $C_{a}$ a axial, $C_{W}$ a velocidade tangencial, $V$ a velocidade relativa e os ângulos são os de entrada ou saída. 
Sabendo a variação de temperatura média por estágio, é possível determinar a relação dos ângulos por meio da Equação 7 (SARAVANAMUTTO et al., 2006).

$$
\Delta T_{O m}=\frac{\lambda \cdot U \cdot C_{a} \cdot\left(\tan \beta_{1}-\tan \beta_{2}\right)}{c p}
$$

Onde $\lambda$ é o fator trabalho que é uma eficiência do estágio do compressor, que cai para cada estágio até um valor de aproximadamente 0,83 no último estágio.

Os ângulos dos componentes também são relacionados com o grau de reação do estágio, que mostra o quanto de energia reativa é transferida para o fluido pelo rotor. $\mathrm{O}$ grau de reação de 0,5 é utilizado em compressores de jatos para garantir que o mesmo transfira energia cinética para o fluido (EL-SAYED, 2017). As equações 8 e 9 mostram essas relações.

$$
\begin{gathered}
\Lambda=1-\frac{C_{a}}{2 U}\left(\tan \alpha_{2}+\tan \alpha_{1}\right) \\
\Lambda=\frac{C_{a}}{2 U}\left(\tan \beta_{1}+\tan \beta_{2}\right)
\end{gathered}
$$

Onde $\Lambda$ é o grau de reação do estágio.

$\mathrm{O}$ estator atua como difusor; e a eficiência com que atua influencia diretamente na eficiência do compressor. Saravanamuttoo et al. (2006) sugerem valores de taxa de difusão superiores a 0,72 . O projeto deve ter algum método para avaliar a difusão permitida, e um dos critérios mais utilizados é o número de Haller, pois permite mensurar a taxa de difusão entre as velocidade relativas de entrada e saída do fluido, conforme apresentado na Equação 10.

$$
0,72 \leq \frac{V_{2}}{V_{1}} \leq 1
$$

\subsubsection{Valores de pressão de estagnação entre estágios}

Para a determinação das propriedades entre os estágios, é necessário que a eficiência $\eta$ do compressor seja levada em consideração (ÇENGEL e BOLES, 2013).

A pressão de saída em cada estágio é descoberta utilizando a relação isentrópica mostrada na Equação 11.

$$
\frac{P o_{2}}{P o_{1}}=\left[1+\left(\eta \cdot \frac{\Delta T o_{m}}{T o_{1}}\right)\right]^{\left(\frac{\gamma}{\gamma-1}\right)}
$$

Onde $\gamma$ é o coeficiente politrópico.

\subsubsection{Dimensões do raio da ponta e da base}

Com a razão entre raios prevista na Tabela 2, é possível encontrar a área do anular na entrada do compressor usando a equação da continuidade, como mostra a Equação 12.

Persp. Online: exatas \& eng., Campos dos Goytacazes, 25 (09) 49 - 76 - 2019 


$$
\dot{m}_{a}=\rho \cdot \pi \cdot R^{2} \cdot\left(1-\left(\frac{r}{R}\right)^{2}\right) \cdot \mathrm{C}_{\mathrm{a}}
$$

Como a densidade aumenta à medida que o fluxo avança é necessário reduzir a área de fluxo e, portanto, a altura da pá. Se a turbina operar a uma velocidade menor que a projetada, a densidade nos últimos estágios será abaixo do valor de projeto resultando em velocidades axiais incorretas que poderão provocar o travamento da lâmina e a sobrecarga do compressor (SARAVANAMUTTOO et al., 2006).

Para que as dimensões do anular e do cubo na saída sejam encontradas, é necessário inicialmente encontrar as propriedades do ar na saída.

Com as equações 11, 12 e 13 é possível determinar as propriedades de estagnação e estáticas na saída.

$$
\begin{gathered}
\frac{T_{0}}{T}=\left(\frac{P_{0}}{P}\right)^{\frac{\gamma-1}{\gamma}}=\frac{T_{02}}{T_{01}}=\left(\frac{P_{02}}{P_{01}}\right)^{\frac{\gamma-1}{\gamma}} \\
T=T_{0}-\frac{C_{a}^{2}}{2 . c p} \\
P=\rho . R . T
\end{gathered}
$$

Onde os termos com subscritos 0 são de estagnação e sem são estáticos. Com esses valores, a equação da continuidade é utilizada para determinar a área na saída.

À medida que o fluido escoa ao longo do compressor o raio do anular reduz, enquanto que o raio do cubo aumenta, de forma a comprimir cada vez mais o fluido (WILSON e KORAKIANITIS, 2014). Em decorrência, a razão entre os raios muda e deve-se fazer um raio médio para se encontrar os valores de saída, assim como uma altura média das lâminas do compressor. As Equações 14 e 15 serão usadas para encontrar respectivamente esses valores.

$$
\begin{aligned}
& r_{m}=\frac{r+R}{2} \\
& h=\frac{A}{2 \cdot \pi \cdot r_{m}}
\end{aligned}
$$

Onde $r_{m}$ é o raio médio e $h$ é o comprimento da lâmina.

O raio do anular na saída do compressor é determinado como o raio médio mais o comprimento da lâmina, enquanto o do cubo é o raio médio menos o comprimento da lâmina. As Equações 16 e 17 demonstram isso, respectivamente.

$$
R_{\text {saída }}=r_{m}+\frac{h}{2}
$$

Persp. Online: exatas \& eng., Campos dos Goytacazes, 25 (09) 49 - 76 - 2019 seer.perspectivasonline.com.br 


$$
r_{s a i ́ d a}=r_{m}-\frac{h}{2}
$$

\subsubsection{Turbina}

A turbina é o equipamento responsável por transformar parte da energia do fluido em energia mecânica. Nela, o fluido em alta pressão e alta temperatura colide com um conjunto de lâminas, transformando a energia do fluido em energia mecânica pela rotação das pás (MASCHIETTO, 2014).

Os dados utilizados na entrada da turbina são considerados os valores da saída da câmara de combustão, conforme mostrados na Tabela 3.

Tabela 3: Propriedades do gás na entrada da turbina

\begin{tabular}{lc}
\hline Propriedade do gás & Valores \\
\hline Calor específico do gás $\left(\boldsymbol{c}_{\boldsymbol{p}}\right)$ & $1,15 \mathrm{~kJ} / \mathrm{kgK}$ \\
\hline Coeficiente politrópico do gás $(\boldsymbol{\gamma})$ & 1,33 \\
\hline Vazão mássica do gás $\left(\dot{\boldsymbol{m}}_{\boldsymbol{g}}\right)$ & $m_{\boldsymbol{a}}$ \\
\hline Temperatura de estagnação da turbina $\left(\boldsymbol{T o}_{\boldsymbol{T}}\right)$ & $1100 \mathrm{~K}$ \\
\hline Eficiência compressor/turbina $(\boldsymbol{\eta})$ & $90 \%$ \\
\hline Coeficiente de fluxo $(\varnothing)$ & 0,8 \\
\hline
\end{tabular}

Para este trabalho e para fins práticos será considerado que a vazão mássica do combustível é relativamente baixa comparado ao fluxo de ar, podendo dessa forma ser desprezada (SIMELANE, 2015).

A abordagem mais simples para o estudo da turbina de fluxo axial é assumir que as condições de fluxo predominantes nos raios médios representam o fluxo de todos os outros raios. Esta simplificação facilita os cálculos e será utilizada na confecção deste trabalho.

Nos estágios da turbina, a expansão do gás produz uma redução da sua entalpia, pressão e temperatura. Como a transformação de energia interna e potencial em cinética acontece somente nos bocais, então, neste caso, as palhetas móveis promovem somente a mudança de direção do fluxo, com transformação da energia cinética em mecânica de acionamento (SARAVANAMUTTOO et al., 2006).

\subsubsection{Trabalho gerado pela turbina}

Segundo Boyce (2012), parte da energia da turbina é utilizada para alimentar o compressor. Considerando a eficiência determinada na Tabela 3, a Equação 18 relaciona a energia gasta no compressor com a energia gerada na turbina, de modo que é possível descobrir a temperatura de estagnação na saída da turbina.

$$
c_{p} \cdot\left(\Delta T_{0 C}\right)=\eta \cdot c_{p g} \cdot\left(T_{0 T 2}-T_{0 T 2}\right)
$$

Onde os subscritos $T$ representam a turbina e $C$ o compressor.

Persp. Online: exatas \& eng., Campos dos Goytacazes, 25 (09) 49 - 76 - 2019 seer.perspectivasonline.com.br 
Sendo assim, o trabalho líquido do conjunto da turbina é dado pela diferença entre a energia gerada na turbina e o trabalho gasto no compressor (MASCHIETTO, 2014). Em uma turbina real existem diversas perdas associadas ao calor, atrito mecânico, cargas e outras irreversibilidades, devido a isto, diversos fatores de correção e rendimentos são utilizados para encontrar as propriedades ao longo do projeto.

Com os valores de estagnação determinados anteriormente, o trabalho líquido da turbina pode ser definido pela Equação 19.

$$
W^{\prime}{ }_{l i q}=\dot{m}_{g} \cdot c_{p g} \cdot\left(T_{0 T 2}-T_{0 T 1}\right)-\dot{m}_{a} \cdot c_{p} \cdot\left(T_{0 C 2}-T_{0 C 1}\right)
$$

\subsubsection{Quantidade de estágios dentro da turbina}

Quando a velocidade no estágio de entrada e saída são iguais $(\mathrm{C} 1=\mathrm{C} 3)$, tem-se uma queda da temperatura estática no estágio $\Delta$ Ts. Com isso, a queda da pressão de estagnação $P_{01} / P_{03}$ pode ser determinado pela Equação 20.

$$
\Delta T_{s}=\eta_{s} \cdot T_{01} \cdot\left(1-\left(\frac{1}{P_{01} / P_{03}}\right)\right)^{\frac{(\gamma-1)}{\gamma}}
$$

Onde $\eta$ s é a eficiência isentrópica do estágio baseada na temperatura de estagnação ou temperatura absoluta. Definida na equação 21.

$$
\eta_{s}=\left(\frac{T_{01}-T_{03}}{T_{01}-T_{3 s}}\right)
$$

Onde $T_{3 s}$ é a temperatura estática atinginda depois de uma expansão isentrópica de $P_{01}$ para $P_{3}$.

Considerando que o ar é expandido enquanto sua pressão é reduzida até determinado valor (que continua sendo maior que a atmosférica), a razão de pressão da turbina permanecerá constante, conforme a Equação 22, sendo possível determinar a quantidade de estágios na turbina.

$$
R_{P}=\left(1+\frac{N \cdot \Delta T_{0}}{T_{01}}\right)^{\frac{\gamma}{\gamma-1}}
$$

Onde $R_{p}$ é a razão de pressão e $N$ é o número de estágios.

\subsubsection{Propriedades entre os estágios da turbina}

Para se calcular as propriedades do gás em cada estágio, é preciso determinar os ângulos das palhetas da turbina. As palhetas de turbinas estacionárias são projetadas de modo a se ter o mínimo de energia cinética dos gases na saída. Esses ângulos são determinados

Persp. Online: exatas \& eng., Campos dos Goytacazes, 25 (09) 49 - 76 - 2019 seer.perspectivasonline.com.br 


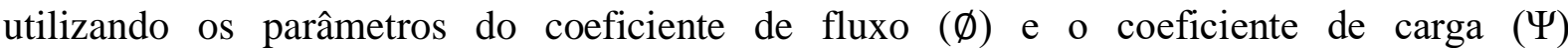
(SARAVANAMUTTOO et al., 2006).

A capacidade de realizar trabalho em um estágio ( $\Psi)$ também é chamado como coeficiente de carga na pá ou coeficiente de queda de temperatura, e a razão $C_{a} / U$ é chamada de coeficiente de fluxo. O coeficiente de carga e o grau de reação podem ser expressos pelas equações 23 e 24 .

$$
\begin{gathered}
\Psi=\frac{2 C_{p} \Delta T_{0 S}}{U^{2}}=\frac{2 C_{\mathrm{a}}}{U}\left(\tan \beta_{2}+\tan \beta_{3}\right)=2 \Phi\left(\tan \beta_{2}+\tan \beta_{3}\right) \\
\Lambda=\left(\frac{\Phi}{2}\right)\left(\tan \beta_{3}-\tan \beta_{2}\right)
\end{gathered}
$$

O ângulo que o fluido desenvolve pode agora ser expresso em termos de $\Psi, \Lambda$ e $\Phi$, e eles podem ser expressos pelas equações 25 e 26.

$$
\begin{aligned}
& \beta_{3}=\tan ^{-1}\left(\frac{1}{2 \Phi}\right)\left(\frac{1}{2} \Psi+2 \Lambda\right) \\
& \beta_{2}=\tan ^{-1}\left(\frac{1}{2 \Phi}\right)\left(\frac{1}{2} \Psi-2 \Lambda\right)
\end{aligned}
$$

Usando as relações do triângulo de velocidade e a definição do coeficiente de fluxo, podemos achar os ângulos $\alpha$ usando as Equações 27 e 28 .

$$
\begin{aligned}
& \alpha_{3}=\tan ^{-1}\left(\tan \beta_{3}-\frac{1}{\Phi}\right) \\
& \alpha_{2}=\tan ^{-1}\left(\tan \beta_{2}+\frac{1}{\Phi}\right)
\end{aligned}
$$

\subsubsection{Dimensões da turbina}

Considerando a vazão mássica do gás constante, a equação da continuidade é utilizada para se obter as áreas de entrada e saída, de forma análoga ao compressor.

Utilizando os valores de velocidade linear média, é possível aplicar sua definição para determinar um raio médio para a turbina, como mostra a Equação 29.

$$
U_{m}=2 \cdot \pi \cdot r_{m} \cdot N
$$

Onde $N$ é a rotação da turbina por segundo.

O comprimento da lâmina é encontrado da mesma forma que no compressor, assim como raio do anular e do cubo.

\section{RESULTADOS E DISCUSSÃO}

Persp. Online: exatas \& eng., Campos dos Goytacazes, 25 (09) 49 - 76 - 2019 seer.perspectivasonline.com.br 
As teorias apresentadas nas seções anteriores foram aplicadas para o projeto do compressor de fluxo axial de um único eixo. O principal desafio para se construir um bom turbofan é alcançar eficiência e estabilidade aerodinâmica para todos os pontos de operação de uma turbina a gás, pois nem sempre ela estará operando em carga máxima.

Para este trabalho a modelagem matemática para os cálculos do comportamento e do desempenho térmico de projeto da turbina a gás foram baseados no método apresentado por Saravanamuttoo et al., segundo o qual é necessário a compatibilização entre as faixas de operação dos diversos componentes da turbina, referentes à vazão mássica, potência e rotação, permitindo determinar o desempenho da turbina a gás para todos os pontos de operação.

Existem, entretanto, valores sugeridos de velocidade na ponta da palheta, velocidades axiais e relações base-ponta para a entrada do primeiro estágio. A área frontal necessária para um dado fluxo de massa será calculada assumindo velocidade axial constante e fazendo uso da equação da continuidade.

\subsection{Compressor}

\subsubsection{Dados de Entrada e Saida}

Os parâmetros de operação foram determinados com base na Tabela 1 e Tabela 2. O pré-dimensionamento do turbofan foi realizado de acordo com as condições estacionárias do voo, sendo desconsideradas as condições transientes de decolagem e pouso do avião. Também foi adotado que a velocidade com que o ar ingressa dentro do compressor é igual à velocidade máxima do avião durante a atitude de cruzeiro.

Considerando o fluido como gás perfeito, relaciona-se a temperatura de estagnação $\left(\mathrm{T}_{0}\right)$ com a estática $(\mathrm{T})$ através da velocidade de entrada do ar no bocal do compressor. E que a vazão mássica do gás é levada ao repouso adiabaticamente sem qualquer transferência de trabalho.

Utilizando as equações 11, 12 e 13, é possível obter os valores de pressão e temperatura estática e de estagnação e densidade estática. $\mathrm{O}$ raio médio, o comprimento da lâmina, o raio do anular e raio do cubo são calculados pelas Equações 14, 15, 16 e 17. Os resultados para esses cálculos são representados na Tabela 4 .

Tabela 4: Dados de Entrada e Saída do Compressor.

\begin{tabular}{lll}
\hline Dados & Entrada & Saída \\
\hline Pressão de estagnação $(\mathrm{kPa})$ & 121,10 & 968,80 \\
\hline Temperatura de estagnação(K) & 216,50 & 418,94 \\
\hline Pressão estática $(\mathrm{kPa})$ & 75,96 & 767,25 \\
\hline Temperatura estática $(\mathrm{K})$ & 189,49 & 391,93 \\
\hline Densidade estática $\left(\mathrm{kg} / \mathrm{m}^{3}\right)$ & 1,40 & 6,82 \\
\hline Área $\left(\mathrm{m}^{2}\right)$ & 0,01 & 0,0027 \\
\hline Raio do anular $(\mathrm{m})$ & 0,07 & 0,06 \\
\hline Raio do cubo $(\mathrm{m})$ & 0,04 & 0,05 \\
\hline Raio médio $(\mathrm{m})$ & 0,0558 & 0,06 \\
\hline
\end{tabular}

Persp. Online: exatas \& eng., Campos dos Goytacazes, 25 (09) 49 - 76 - 2019 seer.perspectivasonline.com.br 


Comprimento da lâmina (m) $\quad 0,0993 \quad 0,0076$

\subsubsection{Determinação do Número de Estágios}

A determinação do número de estágios para que se atinja a compressão pode ser determinada a partir da elevação de temperatura por estágio $(\Delta \mathrm{Ts})$. A variação da temperatura estática entre entrada e saída do compressor $\left(\Delta \mathrm{T}_{0}\right)$ é:

$$
\Delta T o=202,44 K
$$

Para uma velocidade axial fixa, a velocidade de rotação passa a ser função única e exclusivamente da relação entre o raio da base e da ponta. A partir dos valores dos raios da ponta e da base, determinados na Tabela 4 pode-se determinar a velocidade rotacional média na ponta do eixo.

$$
U_{m}=267,03 \mathrm{~m} / \mathrm{s}
$$

$\mathrm{Na}$ análise aerodinâmica de uma pá existem um triângulo de velocidades e diversos ângulos que caracterizam e definem os fenómenos ocorridos na rotação de um rotor.

O triângulo de velocidades é uma forma geométrica de expressar a equação vetorial que relaciona o movimento relativo com o movimento absoluto das partículas fluídas que percorrem o rotor de uma máquina de fluxo. É uma ferramenta indispensável para o estudo simplificado do complexo escoamento através desse tipo de máquina.

A ausência de palhetas guias faz com que a velocidade tangencial seja zero na entrada. $O$ ângulo de entrada do fluido no rotor $\beta_{1}$ é calculado pela Equação 5 considerando o raio médio entre as palhetas e podendo ser deduzidos através dos triângulos de velocidades.

$$
\beta_{1}=48,89^{\circ}
$$

Após determinar o ângulo $\beta_{1}$, é possível determinar a velocidade relativa $V_{1}$ que servirá como parâmetro para obter a velocidade relativa de saída $\mathrm{V}_{2}$, obedecendo ao número de Haller estabelecido para o projeto.

$$
V_{1}=354,4 \mathrm{~m} / \mathrm{s}
$$

As velocidades relativas de entrada e saída do fluido no rotor e estator respectivamente são calculadas pelas equações utilizando um número de Haller cujo valor é de 0,72 para que a deflexão do fluxo de ar no rotor seja possível.

$$
V_{2}=255,165 \mathrm{~m} / \mathrm{s}
$$

O ângulo de saída do fluido no rotor $\beta_{2}$ também é determinado com base no triângulo de velocidades.

$$
\beta_{2}=24,05^{\circ}
$$

Persp. Online: exatas \& eng., Campos dos Goytacazes, 25 (09) 49 - 76 - 2019 seer.perspectivasonline.com.br 
O número de estágios é determinado pelas Equações 3 e 7 a partir da variação de temperatura média por estágio. Este valor pode variar amplamente em cada projeto, sendo que, dependendo da aplicação, podem variar entre 10 a $30 \mathrm{~K}$ para estágios subsônicos, podendo chegar a $45 \mathrm{~K}$ em estágios supersônicos de alta performance.

$$
\Delta T o_{m}=43,31 K
$$

Como já havia sido observado anteriormente no cálculo do número de Mach, o escoamento apresenta características supersônicas, sendo necessário a utilização de pás guias (VIGV) na entrada com o objetivo de reduzir a velocidade de modo a atingir um escoamento subsônico. Sendo assim, é necessário aumentar o número de estágios para se obter variações de temperaturas equivalente ao estado subsônico, levando em consideração que essas pás guias foram utilizadas.

$$
n^{\circ} \text { de estágios } \approx 7 \text { estágios }
$$

Saravanamuttoo et al. (2006) verificaram experimentalmente que a utilização de estágios ímpares de compressão é mais eficiente quando se utiliza baixos estágios de compressão ocorre maior chance de vazamento entre a pás, o que pode acarretar em diversas perdas. Portanto, foi aproximado o número de estágios para 7, de modo a reduzir o aumento da temperatura por estágio e ainda manter a razão de compressão de 8:1, com eficiência de compressão em torno de $90 \%$. Os cálculos do aumento da temperatura do estágio são baseados apenas em considerações de rotor, mas é preciso ter cuidado para garantir que a difusão no estator seja mantida em um nível razoável (SARAVANAMUTTOO et al., 2006).

Na prática, o primeiro e último estágio têm menor variação de temperatura em relação aos demais. A utilização de saltos de temperaturas maiores entre os estágios é interessante para minimizar a quantidade de estágios de uma dada relação. Para este trabalho será utilizado que o primeiro e último estágios terão temperatura média de $26,22 \mathrm{~K}$ e os estágios intermediários cerca de $30 \mathrm{~K}$.

\subsubsection{Determinação das Propriedades de cada Estágio}

O projeto do compressor é considerado sem guias de entrada, portanto, o ângulo de entrada no rotor $\alpha_{1}$ combinado com a velocidade axial é igual a zero. A partir do diagrama de velocidade, vê-se que $\mathrm{C}_{\mathrm{W} 1}$ corresponde a velocidade tangencial do ângulo $\alpha_{1}$ em relação ao vetor da velocidade axial. $\operatorname{Logo}_{\mathrm{W} 1}$ também será zero.

Os resultados do primeiro estágio são demonstrandos na Tabela 5.

Persp. Online: exatas \& eng., Campos dos Goytacazes, 25 (09) 49 - 76 - 2019 
Tabela 5: Dados para o Primeiro Estágio.

\begin{tabular}{ccccc}
\hline Dados & \multicolumn{2}{c}{ Rotor } & \multicolumn{2}{c}{ Estator } \\
\cline { 2 - 5 } & Entrada & Saída & Entrada & Saída \\
\hline Velocidade (Rotor) tangencial média $(\mathrm{m} / \mathrm{s})$ & 263,05 & 263,05 & 0.00 & 0,00 \\
\hline Velocidade axial $(\mathrm{m} / \mathrm{s})$ & 233,00 & 233,00 & 233,00 & 233,00 \\
\hline Velocidade tangencial $(\mathrm{m} / \mathrm{s})$ & 0,00 & 102,22 & 102,22 & 17,29 \\
\hline Velocidade Absoluta & 233,00 & 254,44 & 254,44 & 233,64 \\
\hline Velocidade relativa axial $(\mathrm{m} / \mathrm{s})$ & 233,00 & 233,00 & 233,00 & 233,00 \\
\hline Velocidade relativa rotação $(\mathrm{m} / \mathrm{s})$ & 263,05 & 160,83 & 102,22 & 17,29 \\
\hline Módulo velocidade relativa & 351,40 & 283,12 & 254,44 & 233,64 \\
\hline Alfa (graus) & 0,00 & 23,69 & 23,69 & 4,24 \\
\hline Beta (graus) & 48,47 & 34,62 & 0,00 & 0,00 \\
\hline Temperatura de estagnação $(\mathrm{K})$ & 216,50 & 242,72 & 242,72 & 242,72 \\
\hline Pressão de estagnação $(\mathrm{kPa})$ & 121,10 & 173,59 & 173,59 & 173,59 \\
\hline Deflexão (graus) & $-13,85$ & & \\
\hline
\end{tabular}

A Tabela 6 mostra os resultados do estágio 2.

Tabela 6: Dados para o Segundo Estágio.

\begin{tabular}{ccccc}
\hline Dados & \multicolumn{2}{c}{ Rotor } & \multicolumn{2}{c}{ Estator } \\
\cline { 2 - 5 } & Entrada & Saída & Entrada & Saída \\
\hline Velocidade (Rotor) tangencial média $(\mathrm{m} / \mathrm{s})$ & 263,05 & 263,05 & 0,00 & 0,00 \\
\hline Velocidade axial $(\mathrm{m} / \mathrm{s})$ & 233,00 & 233,00 & 233,00 & 233,00 \\
\hline Velocidade tangencial $(\mathrm{m} / \mathrm{s})$ & 17,29 & 140,54 & 140,54 & 66,40 \\
\hline Velocidade Absoluta & 233,64 & 272,10 & 272,10 & 242,28 \\
\hline Velocidade relativa axial $(\mathrm{m} / \mathrm{s})$ & 233,00 & 233,00 & 233,00 & 233,00 \\
\hline Velocidade relativa rotação $(\mathrm{m} / \mathrm{s})$ & 245,76 & 122,51 & 140,54 & 66,40 \\
\hline Módulo velocidade relativa & 338,65 & 263,25 & 272,10 & 242,28 \\
\hline Alfa (graus) & 4,24 & 31,10 & 31,10 & 15,91 \\
\hline Beta (graus) & 46,53 & 27,74 & 0,00 & 0,00 \\
\hline Temperatura de estagnação $(\mathrm{K})$ & 242,72 & 272,72 & 272,72 & 272,72 \\
\hline Pressão de estagnação $(\mathrm{kPa})$ & 173,59 & 250,59 & 250,59 & 250,59 \\
\hline Deflexão (graus) & $-18,79$ & &
\end{tabular}

A Tabela 7 mostra os resultados do estágio 3.

Persp. Online: exatas \& eng., Campos dos Goytacazes, 25 (09) 49 - 76 - 2019 seer.perspectivasonline.com.br 
Tabela 7: Dados para o Terceiro Estágio.

\begin{tabular}{ccccc}
\hline Dados & \multicolumn{2}{c}{ Rotor } & \multicolumn{2}{c}{ Estator } \\
\cline { 2 - 5 } & Entrada & Saída & Entrada & Saída \\
\hline Velocidade (Rotor) tangencial média $(\mathrm{m} / \mathrm{s})$ & 263,05 & 263,05 & 0,00 & 0,00 \\
\hline Velocidade axial $(\mathrm{m} / \mathrm{s})$ & 233,00 & 233,00 & 233,00 & 233,00 \\
\hline Velocidade tangencial $(\mathrm{m} / \mathrm{s})$ & 66,40 & 196,65 & 196,65 & 62,48 \\
\hline Velocidade Absoluta & 242,28 & 304,89 & 304,89 & 241,23 \\
\hline Velocidade relativa axial $(\mathrm{m} / \mathrm{s})$ & 233,00 & 233,00 & 233,00 & 233,00 \\
\hline Velocidade relativa rotação $(\mathrm{m} / \mathrm{s})$ & 196,65 & 66,40 & 196,65 & 62,48 \\
\hline Módulo velocidade relativa & 304,89 & 242,28 & 304,89 & 241,23 \\
\hline Alfa (graus) & 15,91 & 40,16 & 40,16 & 15,91 \\
\hline Beta (graus) & 40,16 & 15,91 & 0,00 & 0,00 \\
\hline Temperatura de estagnação $(\mathrm{K})$ & 272,72 & 302,72 & 302,72 & 302,72 \\
\hline Pressão de estagnação $(\mathrm{kPa})$ & 250,59 & 348,12 & 348,12 & 348,12 \\
\hline Deflexão (graus) & $-24,26$ & & \\
\hline
\end{tabular}

A Tabela 8 mostra os resultados do estágio 4.

Tabela 8: Dados para o Quarto Estágio.

\begin{tabular}{ccccc}
\hline Dados & \multicolumn{2}{c}{ Rotor } & \multicolumn{2}{c}{ Estator } \\
\cline { 2 - 5 } & Entrada & Saída & Entrada & Saída \\
\hline Velocidade (Rotor) tangencial média $(\mathrm{m} / \mathrm{s})$ & 263,05 & 263,05 & 0,00 & 0,00 \\
\hline Velocidade axial $(\mathrm{m} / \mathrm{s})$ & 233,00 & 233,00 & 233,00 & 233,00 \\
\hline Velocidade tangencial $(\mathrm{m} / \mathrm{s})$ & 62,48 & 200,57 & 200,57 & 62,48 \\
\hline Velocidade Absoluta & 241,23 & 307,44 & 307,44 & 241,23 \\
\hline Velocidade relativa axial $(\mathrm{m} / \mathrm{s})$ & 233,00 & 233,00 & 233,00 & 233,00 \\
\hline Velocidade relativa rotação $(\mathrm{m} / \mathrm{s})$ & 200,57 & 62,48 & 200,57 & 62,48 \\
\hline Módulo velocidade relativa & 307,44 & 241,23 & 307,44 & 241,23 \\
\hline Alfa (graus) & 15,01 & 40,72 & 40,72 & 15,01 \\
\hline Beta (graus) & 40,72 & 15,01 & 0,00 & 0,00 \\
\hline Temperatura de estagnação $(\mathrm{K})$ & 302,72 & 332,72 & 332,72 & 332,72 \\
\hline Pressão de estagnação $(\mathrm{kPa})$ & 348,12 & 468,81 & 468,81 & 468,81 \\
\hline Deflexão & $-25,71$ & & \\
\hline
\end{tabular}

A Tabela 9 mostra os resultados do estágio 5.

Persp. Online: exatas \& eng., Campos dos Goytacazes, 25 (09) 49 - 76 - 2019 seer.perspectivasonline.com.br 
Tabela 9: Dados para o Quinto Estágio.

\begin{tabular}{ccccc}
\hline Dados & \multicolumn{2}{c}{ Rotor } & \multicolumn{2}{c}{ Estator } \\
\cline { 2 - 5 } & Entrada & Saída & Entrada & Saída \\
\hline Velocidade (Rotor) tangencial média $(\mathrm{m} / \mathrm{s})$ & 263,05 & 263,05 & 0,00 & 0,00 \\
\hline Velocidade axial $(\mathrm{m} / \mathrm{s})$ & 233,00 & 233,00 & 233,00 & 233,00 \\
\hline Velocidade tangencial $(\mathrm{m} / \mathrm{s})$ & 62,48 & 200,57 & 200,57 & 62,48 \\
\hline Velocidade Absoluta & 241,23 & 307,44 & 307,44 & 241,23 \\
\hline Velocidade relativa axial $(\mathrm{m} / \mathrm{s})$ & 233,00 & 233,00 & 233,00 & 233,00 \\
\hline Velocidade relativa rotação $(\mathrm{m} / \mathrm{s})$ & 200,57 & 62,48 & 200,57 & 62,48 \\
\hline Módulo velocidade relativa & 307,44 & 241,23 & 307,44 & 241,23 \\
\hline Alfa (graus) & 15,01 & 40,72 & 40,72 & 15,01 \\
\hline Beta (graus) & 40,72 & 15,01 & 0,00 & 0,00 \\
\hline Temperatura de estagnação $(\mathrm{K})$ & 332,72 & 362,72 & 362,72 & 362,72 \\
\hline Pressão de estagnação $(\mathrm{kPa})$ & 468,81 & 615,32 & 615,32 & 615,32 \\
\hline Deflexão (graus) & $-25,71$ & &
\end{tabular}

A Tabela 10 mostra os resultados do estágio 6.

Tabela 10: Dados para o Sexto Estágio.

\begin{tabular}{ccccc}
\hline \multirow{2}{*}{ Dados } & \multicolumn{2}{c}{ Rotor } & \multicolumn{2}{c}{ Estator } \\
\cline { 2 - 5 } & Entrada & Saída & Entrada & Saída \\
\hline Velocidade (Rotor) tangencial média $(\mathrm{m} / \mathrm{s})$ & 263,05 & 263,05 & 0,00 & 0,00 \\
\hline Velocidade axial $(\mathrm{m} / \mathrm{s})$ & 233,00 & 233,00 & 233,00 & 233,00 \\
\hline Velocidade tangencial $(\mathrm{m} / \mathrm{s})$ & 62,48 & 200,57 & 200,57 & 71,18 \\
\hline Velocidade Absoluta & 241,23 & 307,44 & 307,44 & 241,23 \\
\hline Velocidade relativa axial $(\mathrm{m} / \mathrm{s})$ & 233,00 & 233,00 & 233,00 & 233,00 \\
\hline Velocidade relativa rotação $(\mathrm{m} / \mathrm{s})$ & 200,57 & 62,48 & 200,57 & 71,18 \\
\hline Módulo velocidade relativa & 307,44 & 241,23 & 307,44 & 241,23 \\
\hline Alfa (graus) & 15,01 & 40,72 & 40,72 & 15,01 \\
\hline Beta (graus) & 40,72 & 15,01 & 0,00 & 0,00 \\
\hline Temperatura de estagnação $(\mathrm{K})$ & 362,72 & 392,72 & 392,72 & 392,72 \\
\hline Pressão de estagnação $(\mathrm{kPa})$ & 615,32 & 790,34 & 790,34 & 790,34 \\
\hline Deflexão & $-25,71$ & &
\end{tabular}

A Tabela 11 mostra os resultados do estágio 7.

Persp. Online: exatas \& eng., Campos dos Goytacazes, 25 (09) 49 - 76 - 2019 seer.perspectivasonline.com.br 


\section{PERSPECTIVASonlinerâneras Exatas E Engenharia}

Tabela 11: Dados para o Sétimo Estágio.

\begin{tabular}{ccccc}
\hline Dados & \multicolumn{2}{c}{ Rotor } & \multicolumn{2}{c}{ Estator } \\
\cline { 2 - 5 } & Entrada & Saída & Entrada & Saída \\
\hline Velocidade (Rotor) tangencial média $(\mathrm{m} / \mathrm{s})$ & 263,05 & 263,05 & 0,00 & 0,00 \\
\hline Velocidade axial $(\mathrm{m} / \mathrm{s})$ & 233,00 & 233,00 & 233,00 & 233,00 \\
\hline Velocidade tangencial $(\mathrm{m} / \mathrm{s})$ & 71,18 & 191,87 & 191,87 & 71,18 \\
\hline Velocidade Absoluta & 243,63 & 301,84 & 301,84 & 241,23 \\
\hline Velocidade relativa axial $(\mathrm{m} / \mathrm{s})$ & 233,00 & 233,00 & 233,00 & 233,00 \\
\hline Velocidade relativa rotação $(\mathrm{m} / \mathrm{s})$ & 191,87 & 71,18 & 191,87 & 71,18 \\
\hline Módulo velocidade relativa & 301,84 & 243,63 & 301,84 & 241,23 \\
\hline Alfa (graus) & 16,99 & 39,47 & 39,47 & 16,99 \\
\hline Beta (graus) & 39,47 & 16,99 & 0,00 & 0,00 \\
\hline Temperatura de estagnação $(\mathrm{K})$ & 392,72 & 418,94 & 418,94 & 418,94 \\
\hline Pressão de estagnação $(\mathrm{kPa})$ & 790,34 & 968,80 & 968,80 & 968,80 \\
\hline Deflexão (graus) & \multicolumn{2}{c}{} &
\end{tabular}

\subsection{Turbina}

Existem alguns fatores que afetam diretamente a performance das turbinas a gás, como a razão de pressões do compressor, a temperatura de entrada da turbina e a eficiência dos componentes, que para o projeto é da ordem de 90\% (SARAVANAMUTTOO et al., 2006).

A turbina a gás está conectada diretamente a um gerador através do mesmo eixo que conecta o compressor e a turbina. A câmara de combustão não foi objeto de estudo, porém, foi considerado que o ar será elevado até a temperatura de $1100 \mathrm{~K}$ durante a passagem por este componente. Também foi considerada a combustão completa do ar a partir do querosene e que os gases provenientes da combustão terão suas propriedades alteradas conforme previsto na Tabela 4.

Para aplicações aeronáuticas, o que se espera de uma turbina a gás é que ela gere empuxo suficiente para acelerar e manter a aeronave em movimento, e não trabalho mecânico. Porém, é necessário a geração de um trabalho mecânico dos gases resultantes da combustão para movimentar o compressor, fundamental no funcionamento da aeronave. Para isso, as pás da turbina têm sua geometria direcionada para retirar a menor energia possível (BATISTA, 2011).

Desta forma, com base no princípio de conservação de energia, e considerando que o compressor apresenta uma eficiência de $90 \%$, pode-se determinar a temperatura da turbina na saída.

$$
T o_{f}=903,43 K
$$

Uma vez que a eficiência mecânica da turbina não é isentrópica, logo é necessário determinar a temperatura isentrópica para aplicação das propriedades relacionadas a

Persp. Online: exatas \& eng., Campos dos Goytacazes, 25 (09) 49 - 76 - 2019

seer.perspectivasonline.com.br 
isentropia. O cálculo da temperatura isentrópica para uma turbina é determinado com base na eficiência de $90 \%$.

$$
T_{o s}=881,59 K
$$

A partir disso pode-se determinar a pressão na entrada da turbina como a mesma pressão na saída do compressor, considerando que o compressor apresenta uma compressão isentrópica com uma razão de $8\left(P_{01}=r_{p}(12110) P a\right)$.

Portanto, a pressão na saída do compressor é:

$$
P_{01}=(8) .(12110)=96880 P a
$$
isentropia.

Logo, a pressão na saída da turbina pode ser determinada com base nas relações de

$$
P_{o 3}=4 \cdot 10^{4} P a
$$

\subsubsection{Determinação do número de estágios}

Uma vez que a turbina não se expande até a pressão ambiente, é necessário determinar a razão de expansão realizada pela turbina até a saída para que forneça energia suficiente para a geração de energia do compressor. Este valor é obtido a partir da razão entre as pressões $\mathrm{P}_{01}$ e $\mathrm{P}_{03}$.

$$
R_{p}=2,44
$$

O número de estágios necessário para que a razão de expansão seja atingida é:

$$
R_{P}=\left(1+\frac{N \cdot \Delta T s}{T o_{1}}\right)^{\frac{\gamma}{\gamma-1}}
$$

Onde $\Delta T S$ corresponde a diferença de temperatura isentrópica entre a entrada e saída da turbina, portanto:

$$
N=1,386 \approx 2 \text { estágios }
$$

\subsubsection{Determinação do ângulo das palhetas}

Para o projeto de turbina deve ser estudado o escoamento através das passagens entre as palhetas, o qual terá como fundamento principal a teoria de "triângulo de velocidades", que representa um diagrama vetorial com as velocidades absolutas e relativas.

A velocidade absoluta $\mathrm{C}_{1}$ da entrada da turbina no topo e na raiz permanecem iguais, visto que ela independe da posição da palheta. Portanto, a velocidade axial $\mathrm{C} \alpha_{1}=\mathrm{C} \alpha_{3}$ e velocidade absoluta $C_{1}=C_{3}$. Como a turbina não apresenta palhetas guias, $\alpha_{1}=0$. Um ângulo pequeno também é desejado para reduzir perdas e fulgas durante o processo de difusão (SARAVANAMUTTOO et al., 2006).

Persp. Online: exatas \& eng., Campos dos Goytacazes, 25 (09) 49 - 76 - 2019 
A velocidade de rotação é fixada pelo compressor, cujo projeto é sempre mais crítico do que a turbina, já que na turbina ocorre uma desaceleração e redução da pressão. Além disso, a experiência sugerirá um limite superior para a velocidade da lâmina acima da qual há uma tensão severa. Uma vez que o eixo ligado ao compressor é solidário à turbina, a rotação é a mesma $(\mathrm{N}=17000 \mathrm{RPM})$ e uma velocidade média rotacional sobre as pás $\left(\mathrm{U}_{\mathrm{m}}=356,64\right.$ $\mathrm{m} / \mathrm{s})$.

O coeficiente de queda de temperatura $(\Psi)$ na turbina é dado por:

$$
\begin{gathered}
\psi=\frac{2 \cdot c p_{g} \cdot \Delta T s}{U^{2}} \\
\psi=\frac{2 \cdot(1150) \cdot(1100-903,43)}{(340)^{2}}=\mathbf{3}, \mathbf{9 1}
\end{gathered}
$$

Para aeronaves, utiliza-se atualmente valores de $\Psi$ variando entre 3 e 5, e $\Phi$ oscilando entre 0,8 a 1 , pois este valor apresenta uma menor perda por turbilhamento (SARAVANAMUTTOO et al., 2006).

Também será utilizado um coeficiente de perda do bocal que inclui não apenas a perda na volta de entrada, mas também qualquer perda de atrito no espaço sem palheta e a ponta do rotor. O coeficiente de perda pode ser definido usualmente considerando um coeficiente de perda no bocal $(\zeta=0,05)$ (SARAVANAMUTTOO et al., 2006).

\subsubsection{Estágios}

Para o primeiro estágio serão determinados os ângulos para os projetos das pás rotoras e estatoras, assim como as alturas das pás e a temperatura e a pressão na saída desse estágio.

$\mathrm{O}$ ângulo $\beta_{3}$ das palhetas da turbina do estator podem ser determinados considerando que $\alpha_{1}=\alpha_{3}=0$,

$$
\begin{gathered}
\frac{1}{\Phi}=\tan \beta_{3}-\tan \alpha_{3} \\
\frac{1}{0,8}=\tan \beta_{3}-(0) \\
\tan \beta_{3}=1,25 \\
\boldsymbol{\beta}_{3}=\mathbf{5 1}, \mathbf{3 4}^{\circ}
\end{gathered}
$$

É necessário determinar o grau de reação da turbina para verificar se o ângulo adotado para a palheta apresenta uma boa performance.

$$
\Lambda=0,0225
$$

Um grau de reação próximo à zero em relação ao diâmetro médio significa em um baixo escoamento na raiz e consequemente um baixo desempenho da turbina. Os valores negativos certamente devem ser evitados, pois isso implicaria em uma expansão nas palhetas

Persp. Online: exatas \& eng., Campos dos Goytacazes, 25 (09) 49 - 76 - 2019 
seguida de recompressão no rotor e as perdas seriam grandes (SARAVANAMUTTOO et al., 2006). Uma modesta quantidade de turbulência conduziria talvez a um valor mais razoável. Utilizando um ângulo $\alpha_{3}=30^{\circ}$.

Os ângulos das palhetas estatoras e rotoras podem então ser determinados:

$$
\begin{aligned}
\beta_{3} & =61,31^{o} \\
\Lambda & =0,486
\end{aligned}
$$

Este valor é aceitável uma vez que se encontra próximo a 50\%. Portanto, pode-se obter os demais ângulos das palhetas rotoras e estatoras.

$$
\begin{aligned}
& \beta_{2}=31,56^{\circ} \\
& \alpha_{2}=61,78^{\circ}
\end{aligned}
$$

O diagrama de velocidade pode agora ser esboçado como na Figura 4.

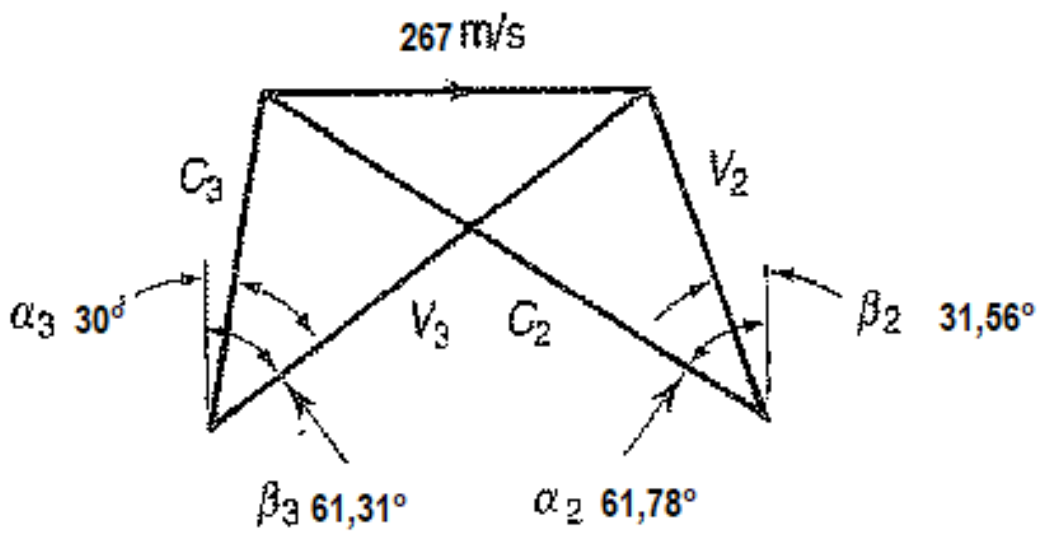

Figura 42: Diagrama de velocidades no primeiro estágio da turbina.

Fonte: Adaptado de Saravanamuttoo et al., 2006.

Para a determinação da área em cada estágio a seção transversal é dividida em 3 partes e a partir do princípio de conservação de massa é determinado a área e a temperatura do fluido em cada um desses pontos conforme ilustra a Figura 5.

Persp. Online: exatas \& eng., Campos dos Goytacazes, 25 (09) 49 - 76 - 2019 seer.perspectivasonline.com.br 


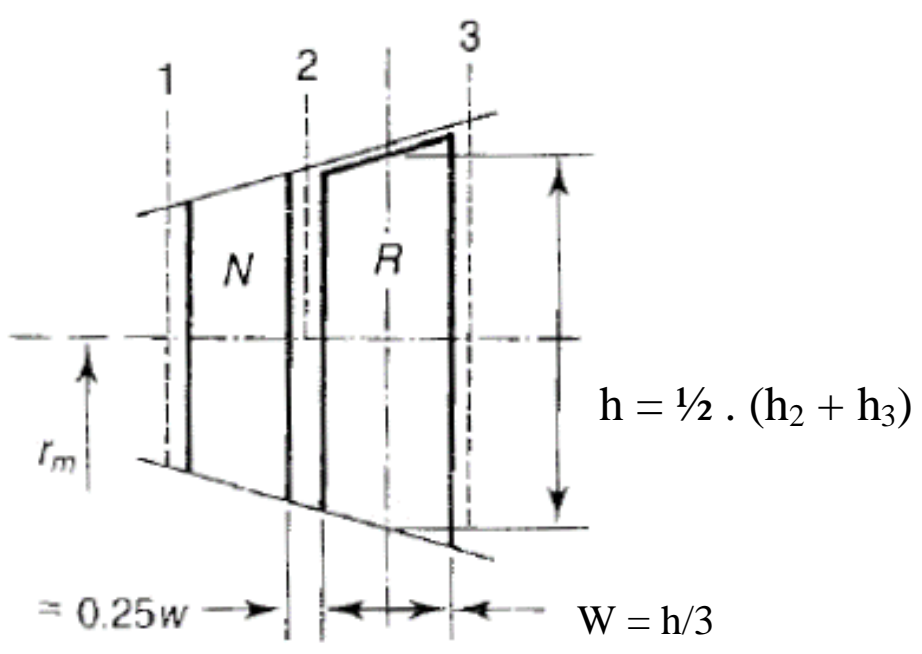

Figura 5: Estágios da turbina.

Fonte: Saravanamuttoo et al., 2006.

Da geometria do triângulo de velocidades pode-se determinar a velocidade axial por:

$$
C_{a 2}=272 \mathrm{~m} / \mathrm{s}
$$

A temperatura de entrada do primeiro estágio após a saída da câmara de combustão é determinada com base nas condições de estagnação.

Uma vez que o segundo estágio não é idêntico ao primeiro será necessário determinar a velocidade axial $C_{1}$ e assume-se que $C_{1}=C_{3}$. A velocidade axial pode-se determinado novamente a partir do triângulo de velocidades.

$$
C_{3}=314,08 \mathrm{~m} / \mathrm{s}
$$

A partir da temperatura de estagnação $\left(\mathrm{T}_{01}=1100 \mathrm{~K}\right)$ determina-se a temperatura $\left(T_{1}\right)$.

$$
T_{1}=1057,11 K
$$

A queda de pressão nesse primeiro estágio pode ser determinada a partir da redução da temperatura.

$$
P_{1}=82531,68 P a
$$

A densidade do ar no primeiro estágio foi determinada com base na equação geral dos gases.

$$
\rho_{1}=0,272 \mathrm{~kg} / \mathrm{m}^{3}
$$

A área de entrada no primeiro estágio da turbina é determinada com base na vazão mássica.

$$
A_{1}=0,0497 m^{2}
$$

Persp. Online: exatas \& eng., Campos dos Goytacazes, 25 (09) 49 - 76 - 2019 seer.perspectivasonline.com.br 
A velocidade $C_{2}$ de saída do primeiro estágio é determinada com base no ângulo $\alpha_{2}$, conforme previsto pelo triângulo de velocidades.

$$
C_{2}=575,22 \mathrm{~m} / \mathrm{s}
$$

Como a temperatura de estagnação na entrada da turbina $\left(\mathrm{T}_{\mathrm{o} 2}\right)$ é $1100 \mathrm{~K}$, a temperatura absoluta na entrada da turbina é:

$$
T_{2}=956,14 \mathrm{~K}
$$

Considerando a perda resultante do coeficiente do bocal pode-se determinar a temperatura isentrópica na saída da turbina no primeiro estágio.

$$
T_{2 s}=948,95 \mathrm{~K}
$$

A pressão na saída do primeiro estágio $\left(\mathrm{P}_{2}\right)$ pode ser obtida a partir da relação isentrópica.

$$
P_{2}=53418,63 P a
$$

A densidade na saída da turbina no primeiro estágio é determinado por:

$$
\rho_{2}=0,195 \mathrm{Kg} / \mathrm{m}^{3}
$$

A área desse estágio pode ser determinada segundo o princípio de conservação da massa.

$$
A_{2}=0,08 m^{2}
$$

A partir da temperatura de saída da turbina $903,43 \mathrm{~K}$ determina-se a temperatura absoluta. Como estabelecido anteriormente a velocidade $\mathrm{C}_{1}=\mathrm{C}_{3}=314,08 \mathrm{~m} / \mathrm{s}$,

$$
T_{3}=860,54 K
$$

A pressão absoluta de saída da turbina:

$$
P_{3}=3,63\left(10^{4}\right) P a
$$

A densidade do ar nesse ponto:

$$
\rho_{3}=0,147 \mathrm{~kg} / \mathrm{m}^{3}
$$

A área na saída do último estágio:

$$
A_{3}=0,092 \mathrm{~m}^{2}
$$

A altura da lâmina em cada estágio pode ser determinada a partir das razões entre os raios do cubo e raiz.

Persp. Online: exatas \& eng., Campos dos Goytacazes, 25 (09) 49 - 76 - 2019 
A equação pode ser rescrita para determinar a altura da pá em cada seção.

$$
\begin{gathered}
h_{1}=\mathbf{0}, 03948 m \\
h_{2}=0,06355 m \\
h_{3}=0,073 m
\end{gathered}
$$

O raio médio pode ser estabelecido com base na equação:

$$
r_{m}=\mathbf{0}, \mathbf{2 m}
$$

A razão da pá na entrada do primeiro, segundo e terceiro estágio:

$$
\begin{aligned}
& \frac{r_{t}}{r_{b}}=1,219 \\
& \frac{r_{t}}{r_{b}}=1,377 \\
& \frac{r_{t}}{r_{b}}=1,4464
\end{aligned}
$$

É necessário verificar o número Mach na saída do estágio, $\mathrm{M}_{3}$, porque se o resultado for muito alto, as perdas por atrito no tubo do jato se tornarão excessivamente grandes. Para este projeto tem-se.

$$
M_{3}=\mathbf{0}, \mathbf{5 4 7}
$$

Que por ser subsônico significa que o pré-dimensionamento está adequado.

\section{CONCLUSÕES}

O objetivo desse projeto foi dimensionar um compressor e uma turbina de propulsão de eixo axial para acionamento do sistema elétrico e empuxo de um de avião a jato Phenom 300E. Para isso foi necessário selecionar uma velocidade rotacional aceitável e calcular as dimensões do compressor e da turbina, determinar o número de etapas, calcular a variação de temperatura e pressão em cada estágio, além de calcular os ângulos de entrada e saída do ar em cada estágio.

A partir dos dados de entrada e em função dos cálculos realizados, concluiu-se que, para a altura e velocidade de cruzeiro do avião apresentado, a velocidade de rotação do compressor e, consequentemente, da turbina, foi de $17000 \mathrm{rpm}$. Com esse valor de velocidade de rotação, foi obtido um número de Mach igual a 1,54 o que caracteriza um escoamento supersônico, que não é ideal para o turbofan, sendo necessário então a utilização de VIGV na entrada do compressor.

As dimensões do compressor foram determinadas a partir vazão mássica que permaneceu constante e igual a $4,25 \mathrm{~kg} / \mathrm{s}$ ao longo do escoamento. Como a densidade do ar varia com a temperatura e a pressão, fez-se necessário determinar a propriedade do ar na saída

Persp. Online: exatas \& eng., Campos dos Goytacazes, 25 (09) 49 - 76 - 2019 
do compressor para a obtenção da área nesse ponto. A pressão e temperatura na saída do compressor foram obtidas a partir da taxa de compressão definida nos parâmetros iniciais do projeto, sendo obtido os valores de $76724,22 \mathrm{~Pa}$ e $391,93 \mathrm{~K}$ para pressão e temperatura, respectivamente. Logo, a área do anular na saída do compressor foi de $0,027 \mathrm{~m}^{2}$. Com o valor da área e, sabendo que a razão entre o tamanho das pontas e raízes das pás do compressor permanece constante e igual a 0,5 , pôde-se descobrir os raios da ponta e da pá na saída do estator $(0,1643 \mathrm{~m}$ e $0,13568 \mathrm{~m}$, respectivamente). Esses valores reunidos correspondem ao dimensionamento do compressor.

Verificou-se que para o compressor são necessários sete estágios de compressão para se obter a razão de compressão arbitrada inicialmente. Em cada estágio, a temperatura, velocidade e ângulo de atuação do ar variam, sendo os valores das velocidades e dos ângulos relacionados ao triângulo de velocidades. No final dos estágios de compressão verificou-se uma razão de compressão de 8,64, condizente com a proposta inicial, e um aumento de temperatura de 202,44 K.

Na turbina há uma diminuição de pressão e temperatura que ocorre com a variação da área e da angulação das palhetas. A partir dos dados arbitrados e obtidos anteriormente, obteve-se uma razão de expansão na turbina de 2,44. Para isso foram necessários 2 estágios de expansão. Em cada estágio a angulação das palhetas sofreu variações determinadas a partir do triângulo de velocidades, de modo a evitar perdas e melhorar o desempenho da turbina, além de serem levados em consideração fatores de correção, como coeficiente de queda de temperatura $(\psi=3,1)$, coeficiente de perda no bocal $(\zeta=0,05)$ e coeficiente de fluxo $(\varnothing=$ $0,8)$ na determinação do grau de reação $(\Lambda=0,486)$, sendo este um valor aceitável, uma vez que se encontra próximo a $50 \%$.

Assim como no compressor, a área do anular varia ao longo da turbina para manter constante a vazão mássica, sendo determinada em função da temperatura, pressão. A área na entrada da turbina foi de $0,0497 \mathrm{~m}^{2}$ enquanto a área na saída da turbina foi de $0,092 \mathrm{~m}^{2}$. Com a variação da área ao longo da turbina foi possível determinar a variação do tamanho das pás. Ao terminar o dimensionamento da turbina, foi verificado o número Mach na saída do estágio, obtendo o valor de 0,547 , que por ser subsônico significa que o pré-dimensionamento está adequado.

\section{REFERÊNCIAS}

ALMEIDA, D. M. M. Microturbina a gás: análise das proporções geométricas do compressor e da turbina no desempenho da microturbina. 2018. 62 p. Dissertação (Mestrado) Faculdade de Ciências e Tecnologia da Universidade Nova de Lisboa, Lisboa, 2018.

BATISTA, V. O. Desenvolvimento e construção da câmara de combustão de uma microturbina a gás. 2011. 72 p. Monografia (Bacharelado) - Engenharia Mecânica, Universidade Tecnológica Federal do Paraná, Pato Branco, 2011.

BOYCE, M.P. Gas Turbine Engineering Handbook. 4th edition. Butterworth-Heinemann, 2012.

BRAGANÇA, F. de V. Turbina a gás: aplicabilidade na marinha mercante. 2014. 71 p.

Persp. Online: exatas \& eng., Campos dos Goytacazes, 25 (09) 49 - 76 - 2019

seer.perspectivasonline.com.br 
Monografia (Bacharelado) - Centro de Instrução Almirante Graça Aranha, Rio de Janeiro, 2014.

ÇENGEL, Y. A., BOLES, M. A. Termodinâmica. 7a ed., McGraw Hill, 2013.

ÇENGEL, Y. A., CIMBALA, J. M. Mecânica dos fluidos: fundamentos e aplicações. AMGH, 2012.

EL-SAYED, A. F. Aircraft propulsion and gas turbine engines. CRC PRESS, 2017.

EMBRAER. Phenon 300E. Disponível em: https://executive.embraer.com/br/pt/phenom300e. Acesso em: 10/05/2019.

JUNIOR, F. de S. Simulação numérica de otimização de projeto de compressores axiais utilizando o método de programação sequencial quadrática. 2007. 129 p. Tese (Doutorado) - Programa de Pós-graduação em Engenharia Mecânica. Universidade Federal de Itajubá, Itajubá, 2007.

LOPES, F de O. Modelo Computacional para Projeto de Compressores Axiais. 2007. 132 p. Dissertação (Mestrado) - Pós Graduação da Faculdade de Engenharia MecânicaUniversidade Estadual de Campinas, 2007.

MARTINELLI JUNIOR, L. C. Máquinas Térmicas II. Panambi, 2002.

MASCHIETTO, Victor C. L. Modelagem das curvas de rendimento de turbinas aeronáuticas turbofan e turbojato. Monografia (Curso de Bacharelado) - Engenharia Mecânica, Universidade Tecnológica Federal do Paraná, Ponta Grossa, 2014.

NECKEL, A. L. Influência da geometria sobre o rendimento de bocais injetores de turbinas tesla no escoamento compressível supersônico. 2013. 93 p. Dissertação (Mestrado) - Programa de Pós-Graduação em Engenharia de Processos e Tecnologias, Universidade de Caxias do Sul, Caxias do Sul, 2013.

PINTO, P. de M. R. Desenvolvimento de Metodologia de Manipulação de Mapas de Características dos Compressores Axiais. 2010. 76 p. Dissertação (Mestrado) - Programa de Pós-Graduação em Engenharia Mecânica, PUC-Rio, Rio de Janeiro, 2010.

POTTER, M. C.; WIGGERT, D. C. Mecânica dos fluidos. $3^{\circ}$. ed. São Paulo: Cengage Learning, 2004.

RIBEIRO, P. M. A. Análise de Performance da Família de Motores de Avião CFM56. 2002. 173 p. Dissertação (Mestrado) - Instituto Superior de Engenharia De Lisboa, Lisboa 2012.

SARAVANAMUTTO, H.I.H., ROGERS, G.F.C., COHEN, H. Gas Turbine Theory 6th Edition. Padston, England: Prentice Hall, 2006.

SIMELANE, P. Axial-compressor and turbine design project for a CESSNA 550 fighterplane. University of Johannesburg, 2015.

Persp. Online: exatas \& eng., Campos dos Goytacazes, 25 (09) 49 - 76 - 2019

seer.perspectivasonline.com.br 
SONNTAG, R. E.; BORGNAKKE, C.; VAN WYLEN. Fundamentos da Termodinâmica. São Paulo: Editora Edgard Blucher, 2013.

WHITE, F.M. Mecânica dos Fluidos. $6^{\text {a }}$ ed. Porto Alegre: AMGH, 2011.

WHITFIELD, A.; BAINES, N. C. A general computer solution for radial and mixed flow turbomachine performance prediction. International Journal of Mechanical Sciences, v. 18, n. 4, p. 179-184, 1976.

WILSON, D. G.; KORAKIANITIS, T. The design of high-efficiency turbomachinery and gas turbines. MIT press, 2014. 